\title{
Usos diplomáticos da ilha-Brasil polêmicas cartográficas e historiográficas*
}

\author{
Diplomatic uses of Brazil's island myth \\ cartographic and historiographic polemics
}

\author{
ÍRIS KANTOR \\ Departamento de História- USP \\ Av. Professor Lineu Prestes, 338- Cidade Universitária \\ São Paulo - SP - CEP 05508-900 - Caixa Postal 8105 \\ ikantor@usp.br
}

\begin{abstract}
RESUMO Este artigo analisa a formação do mito da ilha Brasil e suas representações na cartografia dos séculos XVI e XVII, além das formas de apropriação e reapropriação posterior desse mito com fins diplomáticos.
\end{abstract}

Palavras-chave Historiografia, cartografia, mito da ilha-Brazil

ABSTRACT This article analyses the formation of Brazil's island myth and how it was represented in the XVI and XVII cartography. It also discuss how this myth was used and reused for diplomatic porpoises.

Key words Historiography, Cartography, Brazil's island myth

O Tratado de Tordesilhas, assinado em 7 de junho de 1494, dividiu 0 mundo em dois hemisférios, por um meridiano distante de 370 léguas das ilhas de Cabo Verde, deixando à Espanha tudo que ficasse no Ocidente, e

* Artigo recebido em 17/01/2007. Autor convidado. 
a Portugal o que se contivesse no O riente. 0 acordo estabelecia o prazo de dez meses, contados a partir da data do pacto, para que fosse demarcado o meridiano divisório. ${ }^{1}$ Entretanto, a linha nunca chegaria a ser fixada in situ. Sua localização nos mapas era um exercício de projeção conceptual que não levava em conta nem os aspectos físicos geográficos, nem a ocupação ameríndia do território.

Segundo J aime Cortesão, além das dificuldades técnicas para precisar a longitude, a linha demarcadora amputava a vasta unidade geográfica e humana da formação insular amazônica-platina. Os cartógrafos portugueses teriam falseado as representações do Brasil nas cartas geográficas, fazendo concordar o meridiano com os acidentes geográficos de forma a ressaltar uma suposta fronteira natural dos domínios lusos. ${ }^{2}$ Segundo o estudioso, o delineamento de uma grande lagoa que conectava a bacia platina com a amazônica já era visível nas primeiras descrições geográficas e mapas produzidos por Gaspar Viegas, no Atlas de Lopo Homem (1519), nas cartas de Diogo Ribeiro (1525-27), planisfério de André Homen (1559), no mapas de Bartolomeu Velho (1561).

No Roteiro de todos os sinais na costa do Brasil de Luís Teixeira a representação de um provável encontro entre os rios Paraguai e São Francisco está encoberta por um texto; embora na carta atlântica a mítica ilha-brasil está claramente delineada. O conceito geográfico de ilha-brasil difundese não apenas na cartografia, mas também nas crônicas quinhentistas e seiscentistas, nas quais se identifica que as nascentes do Prata, Amazonas e São Francisco tinham origem num mesmo lago interior. ${ }^{3}$

Passado um século, a cartografia holandesa também incorpora as míticas ilhas ou lagos interiores que conectavam a rede hidrográfica no interior do continente sul americano. ${ }^{4}$ Contudo, segundo Cortesão, é somente nos mapas portugueses que encontraremos uma ligação entre a lagoa dos Xarayés e Eupana, fazendo a conexão entre as bacias do Amazonas, Prata e São Francisco num sistema hídrico único.

Por outro lado, segundo Maria de Fátima Costa, na cartografia espanhola a representação da grande lagoa (que corresponde atualmente à região do Pantanal - Mato Grosso) teria se fixado apenas do século XVII, graças

1 FONSECA, Luis Adão da. O tratado de Tordesilhas e a diplomacia luso-castelhana no século XVI, Lisboa, Edições Enapa, 1991.

2 Cortesão observa que os cartógrafos portugueses diminuíram consideravelmente a distância entre o nordeste brasileiro e 0 arquipélago de Cabo Verde, quer distendendo a chamada costa leste-oeste no sentido do oriente. Da mesma forma, os cartógrafos espanhóis também grafavam o meridiano de Tordesihas à altura da baia de Guanabara... CORTESÃO, J aime. A reação ao tratado de Tordesilhas e o mito da llha Brasil. In: Raposo Tavares e a formação territorial do Brasil, Lisboa, Portugalia, 1966, 2 v., p.42-3.

3 Pero Magalhães de Gandavo, na História da Província de Santa Cruz (c.1570), especialmente no capítulo XIV Gabriel Soares de Souza, 1584; Ambrosio Fernandes Brandão Diálogos das Grandezas do Brasil, Simão Estácio da Silveira, Simão de Vasconcellos (1661) ou Sebastião da Rocha Pita (1730).

4 Como se pode notarnos Atlas de Mercator-Hondius, J ohan Blaeu, Nicolas Sanson e Nicolas de Fer. GOMES, Plínio Freire. 0 Amazonas e o Prata na mitogeografia da América, Revista Topoi, Rio de J aneiro, n.3, p.41-61, 2001. 


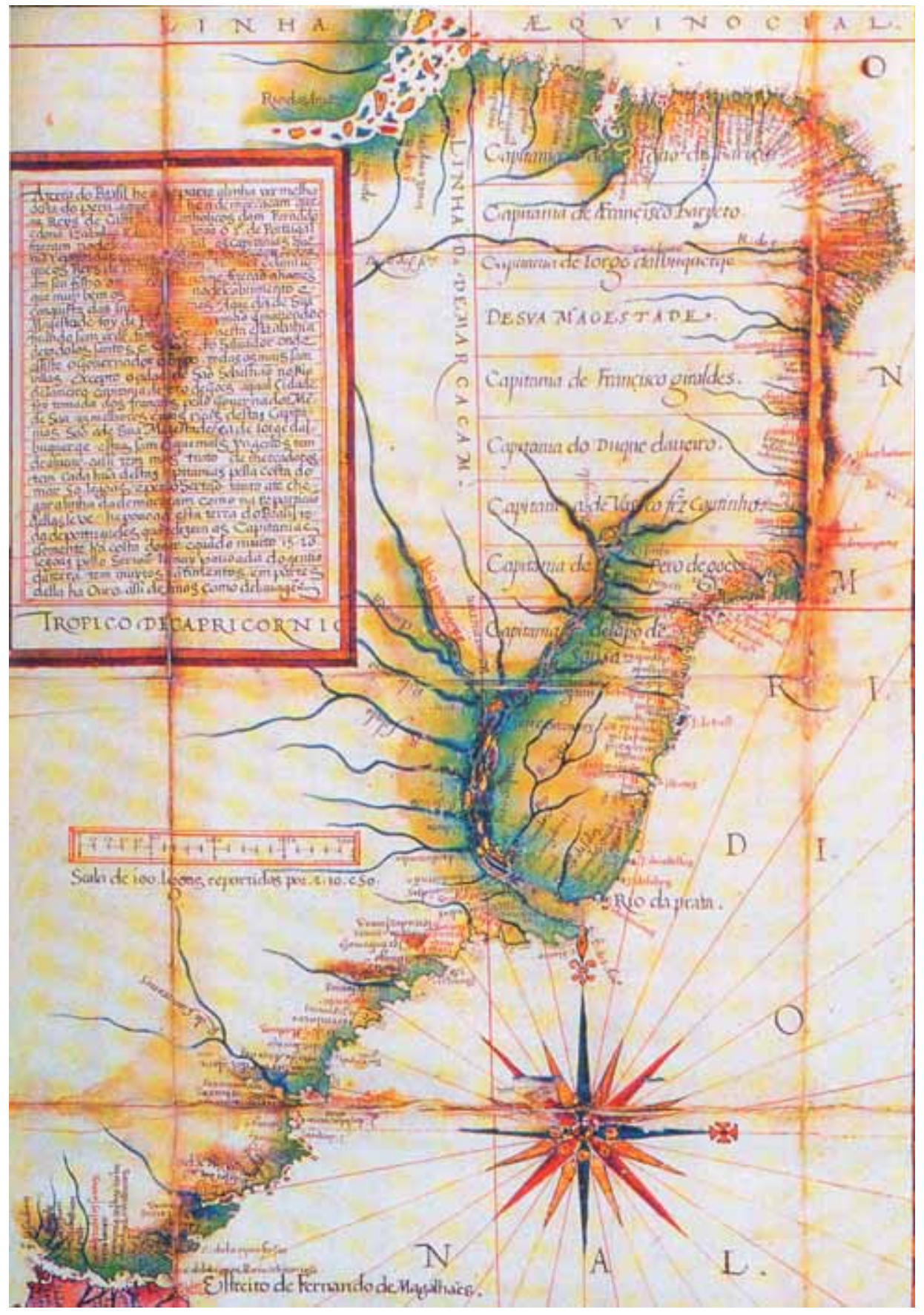

Imagem 1

Roteiro de todos os sinais na costa do Brasil, Luís Teixeira, 1586 (Biblioteca da Ajuda) 


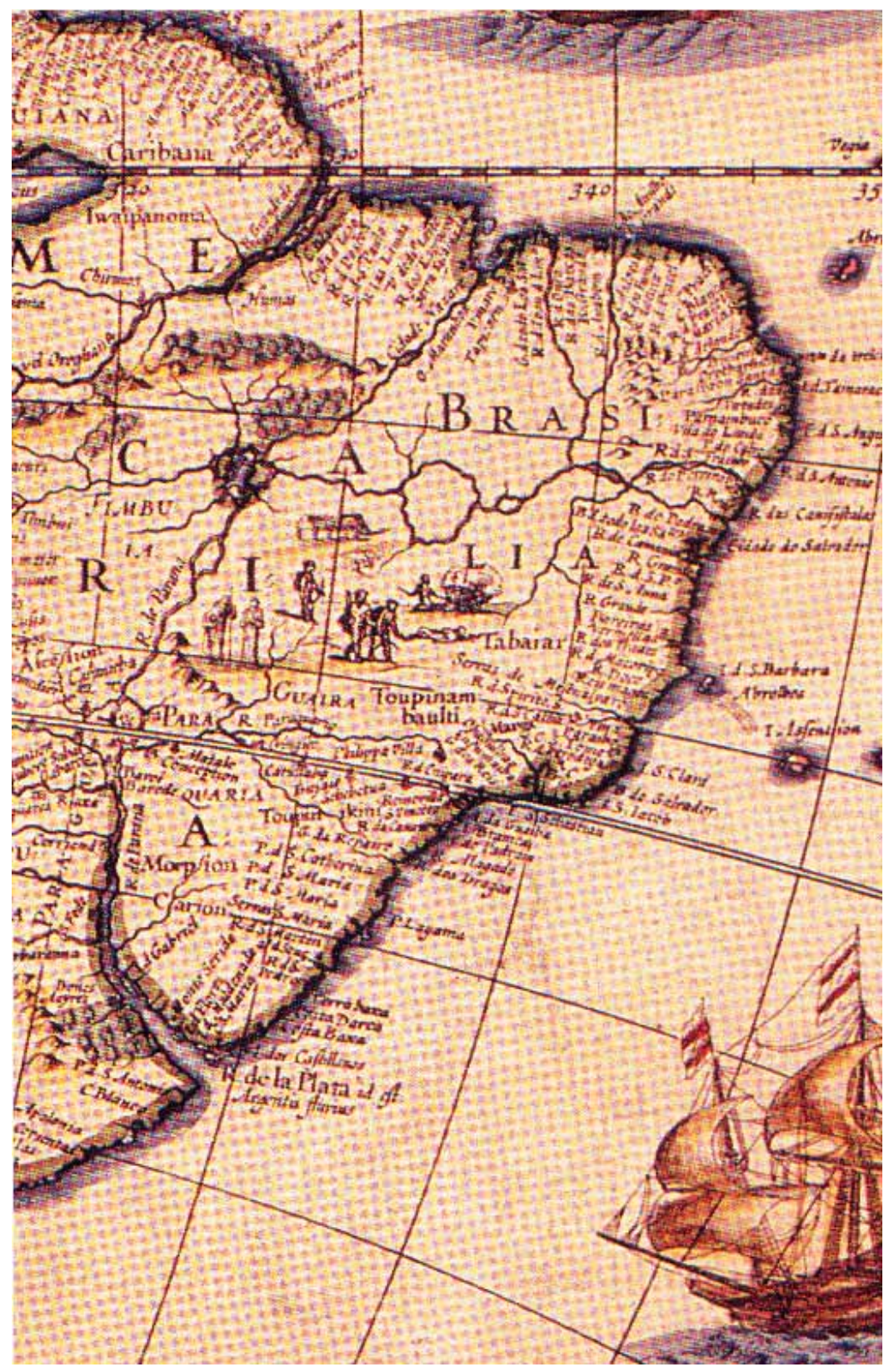

Imagem 2

Williem Blaeu, America Nova Tabula, 1642 
aos relatos de Antonio de Herrera e sua repercussão entre os cartógrafos flamengos e holandeses. ${ }^{5}$ Maria Fernanda Alegria também questiona a hipótese de J aime Cortesão: ${ }^{6}$ se houve um aproveitamento político da representação da ilha brasil , porque ela não foi corrigida pelos cartógrafos estrangeiros contemporâneos, perpetuando-se até praticamente o início do século XVIII?

O mito da insularidade brasílica tinha antecedentes na cartografia medieval, figurando no itinerário das viagens de São Brandão como uma das ilhas (afortunadas) que existiriam no atlântico norte.

Diversos roteiros marítimos, portulanos e planisférios reportavam a existência de uma ilha de Bracir, Brazir ou Bracil localizada entre o cabo de São Vicente e a Irlanda. O Isolario de Benedito Bordoni (Veneza, 1528), apresenta a ilha- Brasil flutuando no Atlântico. ${ }^{7}$ Trata-se de um livro de descrição de ilhas (conhecidos também pelo nome de islários) que fazem um inventário das ilhas descobertas, o gênero remonta à antiguidade clássica, mas adquire grande difusão com a expansão ultramarina. ${ }^{8}$

Uma outra polêmica relacionada com a forma e configuração da massa terrestre americana - sua conexão ou não com o continente asiático - reforçou o debate sobre a insularidade do Brasil até tardiamente. A dúvida se a América era uma ilha ou um continente foi corrente entre cosmógrafos, cronistas e teólogos do Novo Mundo. Ainda em 1758, os acadêmicos brasílicos baianos lançavam o problema aos seus membros: "Se a América é e ilha ou terra firme? E de que parte do Mundo? E como vieram para este Novo mundo os seus primeiros povoadores?". Na cartografia quinhentista a América aparece de duas formas: 1) como uma massa terrestre cercada de água; ou 2) como uma massa terrestre incompleta. A polêmica só seria definitivamente superada com a confirmação de Bering da existência de um estreito ligando o continente americano ao asiático em $1741 .^{9}$

No que diz respeito a representação cartográfica da América como uma ilha, já o Visconde de Santarém, em 1847, tinha observado que desde

5 Maria de Fatima Costa, contudo, chama atenção para a ausência da representação da Lagoa de Xarayes na cartografia portuguesa, discordando nesse aspecto de J aime Cortesão. Segundo a historiadora, a primeira menção a lagoa teria sido feita pelo cronista Antonio de Herrera na sua Historia general de los hechos castellanos em las isla y tierra-firme del mar oceano (1601). COSTA, Maria de Fátima. De Xarayes a Pantanal: a cartografia de um mito geográfico; texto inédito, apresentado no Ciclo: Mapas, Impérios e Colecionismo, Instituto de Estudos Brasileiros e Projeto Temático Dimensões do Império Português, Fapesp, Abril, 2007.

6 ALEGRIA, Maria Fernanda. Representações do Brasil na produção dos cartógrafos Teixeira (1583-1675), Mar Liberum, Lisboa, n.10, 1995.

7 Gustavo Barroso menciona a presença da ilha-Brasil no portulano Médici (1351), no mapa de Picignano ou Pzigani (1367). 0 atlas de Médici traz a ilha com o rótulo de Insula de Brazil. No mapa catalão (1350) a ilha brazil está próxima da Irlanda. Daí uma suposta origem céltica do mito, defendida pelo estudioso. BARROSO, Gustavo. 0 Brasil na lenda e na cartografia antiga, Cia editora Nacional, Rio de J aneiro, 1941, p.99-109

8 LOIS, Carla. América quarta pars: ¿isla o continente? El debate conceptual sobre el estatus geográfico del Nuevo Mundo en el siglo XVI. KANTOR, Iris et alli. (org) Cartografia de uma história São Paulo: Museu Paulista/Cátedra J aime Cortesão. (no prelo)

9 RANDLES, W.G.L. Da terra plana ao globo terrestre. trad. J oão Paulo Oliveira Costa. Lisboa: Gradiva,1990, p.116 
a segunda metade do século XVI os mapas não representavam a América como uma ilha, mas como um continente. A ilha aparece nos mapas de J uan de la Cosa. Mas ele refere-se a um diplomata que, em 1659, considerou 0 Brasil como uma ilha. ${ }^{10}$

Cortesão também utilizou os relatos seiscentistas para fundamentar sua interpretação sobre as origens ameríndias da ilha Brasil. Citando o padre jesuíta Simão de Vasconcelos, ele observou que os indígenas atuaram como cosmógrafos rústicos, transmitindo oralmente as informações sobre o interior do continente aos colonos. Reconheceu, contudo, que a expressão cartográfica do mito da ilha brasil é resultado de uma cartografia estatal dirigida. Cortesão insiste na hipótese, hoje questionável, de que os mapas portugueses traziam sempre as longitudes falseadas, como parte da política de sigilo adotada pela diplomacia portuguesa. Assim, as informações estratégicas eram preservadas com o objetivo de impedir o avanço dos concorrentes na disputa inter-imperial européia.

Em 1952, por ocasião da edição do livro Raposo Tavares, de J aime Cortesão, Sérgio Buarque de Holanda, nas páginas do Diário Carioca e na Folha da Manhã, contestou a tese da ilha Brasil. ${ }^{11} 0$ historiador paulista argumentou contra a idéia de uma razão de Estado geográfica implícita no movimento bandeirista, rebatendo, sobretudo, a hipótese de que ele fazia parte de um programa expansionista do Estado português pré-definido. Também criticou a tese segundo a qual o suposto mito da ilha Brasil teria sido instrumentalizado, quer pela Coroa, quer pelos colonos.

Em trabalho recente, André Ferrand de Almeida explora a argumentação proposta por J aime Cortesão, distinguindo dois planos da controvérsia: 1) as representações cartográficas do mito; 2) sua repercussão no processo de apropriação do território. No que toca aos segundo plano, diz o autor, não convém estabelecer uma associação direta entre o mito e o movimento das Bandeiras. Dado que o bandeirismo não era um empreendimento propriamente estatal, mas impulsionado pelos interesses locais. ${ }^{12}$ Embora a fulguração de riquezas minerais associadas à lagoa Dourada talvez tivesse exercido algum encanto entre os apresadores de índios.

Enfim, o fato é que até a chegada dos holandeses a produção cartográfica estava concentrada na representação da costa, sem uma preocupação em detalhar o interior do continente. Interessava conhecer e mapear os acidentes geográficos e nomear o litoral. A Coroa portuguesa não tinha

10 SANTAREM, Visconde de. História das relações diplomáticas. Tomo IV, segunda parte, introdução CXIX.; Sur la question de savoir à quelle époque l'Amérique méridional a cessé d'etre representée dans les cartes géographiques comme une ile d'une grande étendue, 1847.

11 HOLANDA, Sérgio Buarque de. Um mito geopolítico: a ilha Brasil. In: Tentativa de Mitologia. São Paulo: Perspectiva, 1979. Publicado também na edição no Diário Carioca, RJ , 22 de junho de 1952, seção 2, p.3, e 29 de junho de 1952, seção 2; Folha da manhã, 24 de junho de 1952, 1 de julho, 10 de julho.

12 ALMEIDA, André Ferrand de. A Formação do espaço brasileiro e o projeto do Novo Atlas da América portuguesa. Lisboa: CNCDP, 2001, p.42-45. 
intenção de controlar territórios, mas, sobretudo, de defender suas rotas marítimas e comerciais preferenciais. A representação do interior do continente naqueles mapas constituía uma metáfora das possibilidades de apropriação do espaço real. Neles se traçava uma entidade geográfica, em que eram dispostos alguns elementos ou signos que remetiam a direitos de domínio ou titularidade da posse dos territórios dos impérios (Bandeiras, Brasões, Fortes e Fortalezas, linha das Tordesilhas). Com o estabelecimento da Companhia das Índias Ocidentais no Nordeste, um novo impulso foi dado à cartografia terrestre e ao mapeamento in loco do interior dos sertões brasílicos.

A história do uso dos mapas na diplomacia internacional é também a história da fixação e difusão de certos erros cartográficos. Contudo, não se pode tomar tais "erros" como "inverdades absolutas", pelo contrário, sua identificação nos permite entender dinâmicas políticas tanto locais, quanto imperiais. Nem todos os erros, obviamente, comportam transcendência geopolítica, como foi o caso do mito da ilha Brasil. A existência ou não de uma ilha Brasil seria um desses mal-entendidos que foram cultivados tanto pela diplomacia portuguesa, quando pela diplomacia imperial brasileira oitocentista. ${ }^{13} 0$ mito constituiria, assim, uma pré-figuração geográfica do Brasil Independente, tendo sido aproveitado tanto pelo Estado português, quanto pelo Estado pós colonial, um mito fundador da herança lusitana. J aime Cortesão apresenta a situação da seguinte forma: "pouco a pouco um dos alvos da metrópole e dos colonos; dos dirigentes e dos dirigidos; do Estado e da iniciativa particular; dos lusos e dos luso-brasileiros...". ${ }^{14}$

Advogando a tese da intencionalidade dos erros cartográficos para defender a eficácia da diplomacia portuguesa, J aime Cortesão remarca a importância da cartografia como instrumento jurídico. A defesa da continuidade ou contigüidade das fronteiras fluviais era um argumento legítimo no processo de demarcação das fronteiras, tendo em vista a prevalência do princípio da fronteira natural nas negociações internacionais. O historiador reiterou sua perspectiva ao analisar o Mapa das Cortes, encomendado por Alexandre de Gusmão para negociar o Tratado de Madri, em 1750. Neste caso, o erro cartográfico - de 9 graus (no sentido da costa leste) na localização da vila de Cuiabá - permitiu ampliar as possessões portuguesas, fazendo recuar a linha imaginária.

Maria Fernanda Alegria também estudou uma série de mapas dos séculos XVI e XVII, procurando identificar as lógicas que presidiram o traçado da linha de Tordesilhas. Ela atesta a enorme flutuação da linha, que corta, indistintamente, o continente em direção vertical do Delta Amazônico

13 MAGNOLI, Demetrio. 0 corpo da pátria: imaginação geográfica e política externa no Brasil. São Paulo: UnespModerna, 1997.

14 CORTESÃO, J aime. A reação ao tratado de Tordesilhas e o mito da IlhaBrasil. In: Raposo Tavares , p.62. 
a Cananéia, Santa Catarina ou Lagoa dos Patos. ${ }^{15}$ Como se sabe, a partir da Restauração portuguesa, a definição da linha do meridiano implicava a defesa da soberania lusa no estuário platino, tendo sido fruto de intensas negociações diplomáticas desde fins do século XVII, por ocasião da assinatura do Tratado Provisional de 1681. Quando da fundação da Colônia do Sacramento, em 1680, invocava-se a demarcação virtual do meridiano de Tordesilhas.

\section{Mapas pós-Westfalia e a coroa portuguesa}

Desde a paz de Westfalia (1648), os mapas tornaram-se parte do argumento jurídico de definição das fronteiras e limites territoriais entre os diferentes Estados imperiais europeus. Está em gênese uma nova concepção de soberania articulada com um território espacialmente definido. Nesse sentido, os mapas tornaram-se testemunhos de uma tensão permanente entre o domínio nominal e o domínio efetivo e seus efeitos no plano internacional.

Estamos já distantes do paradigma do século XVI, em que a figuração e as alegorias podiam preencher os espaços vazios nas cartas geográficas. Após as polêmicas do mare Liberum ou mare clausum, deflagradas pela Companhia das Índias e por Hugo Grotius, os mapas seriam investidos de uma aura de fidedignidade que não possuíam nos séculos anteriores. Já não são mais apenas bens artísticos de prestígio nas negociações internacionais, mas também parte vital da reivindicação do monopólio colonial.

Logo após a Guerra dos Trinta Anos, vieram à luz numerosas discussões sobre a autenticidade dos diplomas de demarcação territorial nas regiões do Sacro Império, as quais desencadearam uma verdadeira guerra de "títulos de posse", travada nos tribunais alemães. Os adversários, de um e outro lado, apresentavam memórias e aparatos jurídicos com que procuravam assegurar seus direitos históricos territoriais. ${ }^{16} 0$ Tratado de Westfalia inaugurava uma atitude secularizante frente ao problema do domínio e soberania territorial, esvaziando 0 direito de arbitragem papal. ${ }^{17}$ O ficialmente excluído do Tratado de Westfalia (Münster, 1648), por exigência da Espanha, de Veneza e da Santa Sé, Portugal foi então forçado a aceitar a doutrina do Mare Liberum de Grócio, posição que implicava revisões da bula Inter Coetera e do Tratado de Tordesilhas (1494)..$^{18}$

15 ALEGRIA, Maria Fernanda. Representações do Brasil na produção dos cartógrafos Teixeira (1583-1675).

16 RODRIGUES, J osé Honório. Teoria da história do Brasil. São Paulo: Cia. Editora Nacional, 1969, p.240. NORDMAN Daniel. Les Titres et les Preuves: La notion de droits historiques en France (1648-1661). In: BELY, Lucien. L'Europe des traités de Westfalie. Paris: PUF, 2000, p.244-252.

17 MACEDO, Jorge Borges de. História diplomática portuguesa: constantes e linhas de força. Lisboa: Instituto da Defesa Nacional, 1987, p.175; CLUNY, Isabel. D. Luís da Cunha e a idéia de diplomacia em Portugal. Lisboa: Livros Horizonte, 1999, p.99-102.

18 Ver FRANÇA, Eduardo D’Oliveira. Portugal na época da Restauração. São Paulo: Hucitec, 1997. 
Grócio questionou as condições do dominium (não como direito de jurisdição, mas como posse de bens) e do alegado monopólio de navegação ibérico nos mares nunca navegados. ${ }^{19}$ Advogado da Companhia das Índias Orientais, opôs-se à argumentação portuguesa, rejeitando a legitimidade da doação pontifícia e as prerrogativas advindas da prioridade nos descobrimentos, assim como a justificativa de ocupação por costume ou por guerra justa nos mares e terras asiáticos. Descobrir, na concepção de Grócio, era "tomar posse de" uma região que devia ser formalmente res nullius. ${ }^{20} \mathrm{O}$ descobrimento só poderia criar títulos de domínio se acompanhado da posse, isto é, de bens móveis, se estes fossem apreendidos, ou, tratando-se de imóveis, se demarcados por meio de limites precisos e guardados por força permanente. ${ }^{21}$ Referindo-se à presença de padrões portugueses ou às cruzes de madeira espanholas nas rotas de navegação e nas costas, ele negava o valor jurídico dos cerimoniais de posse como critério de primazia e precedência na conquista. ${ }^{22}$ Argumento aliás que será restaurado pela diplomacia portuguesa no século XIX.

0 ataque não ficou sem resposta. Do lado português, o canonista de Valladolid, Serafim de Freitas (De lusto Imperio Lusitanarum Asiatico, 1625), refutou o jurista neerlandês, afirmando o direito e a obrigação dos reis cristãos de evangelizar os povos gentios e infiéis. Do título de descobrimento derivava o princípio de ocupação, porque, se a Ásia era conhecida, esse conhecimento era imperfeito, como provavam os inúmeros erros cartográficos cometidos pelos antigos quanto às terras e mares para além do cabo da Boa Esperança. Serafim de Freitas também discorreu sobre a aquisição de um direito por prescrição imemorial (decorridos mais de 100 anos) ou por direito consuetudinário.

O debate sobre a soberania nos mares e terras distantes balizou a elaboração de novos conceitos de soberania territorial na passagem do século XVII ao XVIII. O novo paradigma suplantaria os pressupostos teológico-políticos que asseguravam a incorporação dos espaços ainda não conhecidos e dominados numa totalidade representada por um virtual Império cristão universal. A tensão entre uma concepção teológico-política e uma visão

19 GROTIUS, Hugo. Do Direito da Paz e da Guerra. In: Textos Clássicos de Filosofia do Direito. Traduzido por Nelson F. Carvalho. São Paulo: Editora Revista dos Tribunais, 1981. Ver também o artigo de GESTEIRA, Heloisa Meireles. Da Liberdade dos mares: Hugo Grotius e a soberania do Imperium. In: MUNTEAL FILHO, Oswaldo et alli. Olhares sobre o político. Rio de J aneiro: Ed.UERJ , 2002, p.175-190. PADGEN, Anthony. Commerce and Conquest: Hugo Grotius and Serafim de Freitas on the freedom of the sea. Mare Liberum, Lisboa, v.20, p.33-55, 2000.

20 “(...) entre nós e os Hispanos está em controvérsia: se o acesso ao imenso e vasto mar pode ser reservado a um só reino, que por sinal não é o maior de todos; se um povo pode ter o direito de proibir outros, desejosos de 0 fazer, de entre si comprarem, venderem, permutarem e comunicarem; se alguém pode fazer concessões daquilo que nunca foi seu ou adquirir o que já era de outros; e se uma injustiça prolongada pode criar um direito." Apud CAETANO, Marcelo. Portugal e a internacionalização dos problemas africanos. Lisboa: Edições Áticas, 1971, p.44.

21 HOLANDA, Sérgio Buarque de. Visão do paraíso. São Paulo: Companhia Editora Nacional, 1985, p. 310.

22 SEED, Patrícia. Cerimônias de posse na conquista européia do Novo Mundo (1492-1640). Tradução Lenita Esteves. São Paulo: Unesp/Cambridge, 1999, p.145/172. 
secular da soberania se aprofundava à medida que a fronteira colonial avançava, tornando a presença dos missionários jesuítas uma contradição insuperável. Duas concepções de territorialidade se enfrentaram na segunda metade do século XVIII, levando à expulsão dos jesuítas, não só do Império português, como dos demais impérios católicos na Europa.

Encerrando uma guerra de 14 anos, foi assinado o Tratado de Utrecht (1712-5), no qual eram redefinidas as posições estratégicas das potências européias. A casa de Bourbon assumia o trono espanhol. Portugal recebeu os territórios na foz do Amazonas, e os espanhóis restituíram a Colônia do Sacramento. A França perdeu seu território na Lorena, América do Norte, mas continuou pretendendo ocupar os territórios do Cabo do Norte. ${ }^{23}$ Entretanto, a maior parte do território do Alto Amazonas permaneceu sendo uma zona de fronteira litigiosa entre portugueses e espanhóis. 0 fim da União Ibérica trouxe à baila a indefinição jurisdicional daquele imenso território ocupado pelas comunidades indígenas e pelas missões religiosas de jesuítas, franciscanos e carmelitas, submetidos, por sua vez, ao Padroado Régio português ou ao Patronazgo espanhol. ${ }^{24}$

Significativamente, o relato da viagem de reconhecimento pelo rio Amazonas, do Pará até Quito - comandada pelo capitão português Pedro Teixeira (1637-39) às vésperas da ruptura da União Ibérica - passa a ser disputado pelas duas Coroas Ibéricas como um título de posse, cada qual alegando que a iniciativa da expedição havia partido do seu lado. ${ }^{25}$

A diplomacia francesa questionou o Tratado de Utrechte as pretensões portuguesas tanto na região do Cabo Norte, como na Colônia do Sacramento, valendo-se para isso de um mapa especialmente preparado pelo cosmógrafo Guillaume Delisle, apresentado na Academia de Ciências de Paris em 1720. Segundo o cosmógrafo francês, a linha de Tordesilhas tinha sido afastada para o Oriente. ${ }^{26}$ Diversas cartas trocadas entre o diplomata

23 Cf. BICALHO, M. Fernanda. A Cidade e o Império: Rio de J aneiro no século XVIII. 1. ed. Rio de J aneiro: Civilização Brasileira, 2003; FIGUEIREDO, Luciano Raposo de. O Império em apuros: notas para o estudo das alterações ultramarinas no Império Português, séculos XVII e XVIII. In: Furtado, J .. (org.). Diálogos oceânicos: Belo Horizonte: EdUFMG, 2001, p.197-254; e SOUZA, Laura de Mello e. La conjoncture critique dans le monde luso-brésilien au début du XVIII siècle. Arquivo do Centro Cultural Calouste Gulbenkian, Paris/Braga, p.11-24, 2001.

24 Auxiliomar Silva Ugarte trabalha a noção de fronteira política e cultural nas crônicas missionárias e em relatos de expedições militares na região ocidental da Amazônia seiscentista, confrontando as diferenças de significado entre ser vassalo do rei da Espanha e do rei de Portugal. UGARTE, Auxiliomar Silva. Filhos de São Francisco no País das Amazonas: catequese e colonização na Amazônia do século XVII. Amazônia em Cadernos, Manaus, n.6, p.200-27, jan./dez. 2000; Ao Serviço de Deus e de Sua Majestade: a conquista da Amazônia no imaginário político dos conquistadores ibéricos (século XVI-XVII), 2000, exemplar cedido pelo autor, ainda inédito; Cronistas: os porta-vozes da conquista ibérica da Amazônia, 2000, exemplar cedido pelo autor, ainda inédito. Agradeço ao autor a oportunidade de ler seus trabalhos, bem como suas sugestões de bibliografia e documentação.

25 TEIXEIRA, Pedro. Relazion del General Pedro Teixeira de el rio de las Amazonas para el Senhor Príncipe. (1639). In: CORTESÃO, Jaime. O significado da expedição de Pedro Teixeira à luz de novos documentos, Anais do IV CONGRESSO DE HISTÓRIA NACIONAL. Rio de J aneiro, IHGB/IBGE,v.3, p.188-194; ABREU, Capistrano de. Formação dos limites. In: Capítulos de história colonial. São Paulo: Itatiaia/Publifolha, 2000, p.207.

26 Dissertação de Mr. Delisle L'Ainé sobre a situação exacta das diferentes partes da terra e na qual se nega que o Cabo do Norte e a Colônia do Sacramento pertençam à zona de soberania portuguesa, determinada pelo meridiano de Tordesilhas, 27 de novembro de 1720. In: CORTESÃO, J aime. (org.) Antecedentes do Tratado (de Madri). Rio de J aneiro: Instituto Rio Branco, s.d., tomo 1, p.206-221. 
D. Luís da Cunha e o secretário de Estado Diogo de Mendonça Corte Real revelam a preocupação com o mapa proposto por Delisle e sugerem a necessidade de aprimorar o cálculo das longitudes. ${ }^{27}$ De toda maneira, nessa altura, a diplomacia portuguesa já admitia a necessidade de uma revisão técnica do meridiano de Tordesilhas. ${ }^{28}$

É importante destacar que a necessidade de redefinição do Tratado de Tordesilhas não era novidade, mas fazia parte dos desdobramentos políticos do fim da União Ibérica na América e nas ilhas Filipinas. ${ }^{29} 0$ comandante Francisco Brito Freire também escreveu em sua crônica militar que os homens que tratavam das linhas divisórias "nunca desembaraçam bem a meada, que se fez dessas linhas". ${ }^{30}$ Importa sublinhar que a concepção de uma ilha-Brasil foi utilizada com engenho pelos diplomatas portugueses (tendo sido, obviamente, rejeitada pelos espanhóis) para justificar a fundação da Colônia do Sacramento e os direitos portugueses à margem oriental do Prata. ${ }^{31} 0$ uso do argumento da fronteira natural já estava claramente formulado nas negociações luso-espanholas de 1680, após a fundação da Colônia do Sacramento. ${ }^{32}$ A diplomacia portuguesa estava atenta para 0 valor prático do conceito de fronteira natural, que fazia coincidir os acidentes naturais com as jurisdições políticas.

Com a assinatura do Tratado de Madri (1750) estabelecia-se o princípio da posse efetiva, o chamado uti possidetis, e aboliam-se definitivamente as disposições da doação pontifícia (bula Inter Coetera), sendo revogado o Tratado de Utrecht. $O$ historiador Luís Ferrand de Almeida chamou a atenção para o fato de que o princípio de fronteira natural seria, ainda, o principal instrumento de demarcação utilizado pelas comissões luso-hispânicas. ${ }^{33}$ Portanto, é nesse contexto que o mito da ilha Brasil é mobilizado, agora, porém, já como uma ideologia geográfica, mais do que como um saber em que se projetavam os horizontes de expectativas da colonização.

27 Delisle propunha um cálculo baseado no método astronômico da observação dos eclipses dos satélites de J úpiter, fazendo uso das observações astronômicas de missionários jesuítas situados em diversas partes do planeta. Diogo de Mendonça Corte Real sugeria que o Padre Bartolomeu Lourenço de Gusmão preparasse uma resposta oficial da Coroa portuguesa. Cartas entre Diogo de Mendonça Corte Real para D. Luís da Cunha (30-9-1720/7-10-1721/ 19-11-1721). In: CORTESÃO, J aime. (org.). Antecedentes do Tratado (de Madri), p.206-229.

28 ALMEIDA, André Ferrand de A formação do espaço brasileiro e o projeto do Novo Atlas da América Portuguesa: 1713-1748, p.28-66. Desde Londres, em 1721, J acob de Castro Sarmento enviava à Academia Real de História Portuguesa uma Nova Descrição do Globo ou Exacta Medida dos Impérios, Reinos, Territórios, Estados Principais, Condados e Ilhas de todo Mundo..., cf. CUNHA, Norberto Ferreira da. Elites e acadêmicos na cultura portuguesa setecentista. Lisboa: Casa da Moeda/Imprensa Nacional, 2001, p.69.

29 ALMEIDA, André Ferrand de A formação do espaço brasileiro e o projeto do Novo Atlas da América Portuguesa: 1713-1748, p.316.

30 FREIRE, Francisco de Brito. Nova Lusitânia: história da Guerra Brasílica. Lisboa, 1675, item 89.

31 ALMEIDA, Luís Ferrand de. A Colónia do Sacramento na época da sucessão de Espanha. Coimbra: Faculdade de Letras da Univ. de Coimbra, 1973, p.43. Sobre o mito da ilha-Brasil, ver CORTESÃO, J aime. Raposo Tavares e a formação territorial do Brasil.

32 ALMEIDA, Luís Ferrand de. A Colónia do Sacramento na época da sucessão de Espanha, p.317.

33 ALMEIDA, Luís Ferrand de. A Colónia do Sacramento na época da sucessão de Espanha, p.318. 